\title{
EU-WIDE NETWORKING: AN INSTRUMENTAL VALUABLE FOR EUROPEAN RURAL DEVELOPMENT POLICIES IN ROMANIA ${ }^{1}$ ?
}

\author{
Doris Marquardt ${ }^{2}$, Judith Möllers and Gertrud Buchenrieder
}

Received 3 July 2009; Accepted 18 September 2009

\begin{abstract}
This paper examines the relevance of networking as an instrument for implementing European rural development policies. The LEADER programme of the European Union (EU) supports partnerships and networking within and between rural regions in the EU and aims at advancing rural, regional socio-economic development. LEADER and the establishment of the European and National Networks for Rural Development, respectively, are discussed using the example of the case of Romania, where these measures are currently implemented. The discussion is primarily based on results of 2008 surveys among various stakeholders involved in LEADER in Romania, Hungary and Germany. We conclude that networking is a key factor for successfully implementing rural development policies. This is due to benefits resulting from the exchange of experiences or partnerships, but also due to social control - a hidden effect of networking.
\end{abstract}

Key words: Rural development policies, LEADER, European Network for Rural Development, networking, Romania

Zusammenfassung: Dieser Beitrag befasst sich mit der Bedeutung von Netzwerken als Instrument zur Umsetzung der europäischen Politik zur Entwicklung des Ländlichen Raums. Durch das EU-Programm LEADER werden Partnerschaften und Netzwerkaktivitäten in und zwischen ländlichen Regionen unterstützt mit dem Ziel einer Förderung ihrer sozioökonomischen Entwicklung. LEADER sowie der Aufbau des Europäischen und des Nationalen Netzwerks für den Ländlichen Raum werden im Hinblick auf die Situation in Rumänien diskutiert, wo derzeit diese Maßnahmen eingeführt werden. Der Beitrag stützt sich vor allem auf Ergebnisse von im Jahr 2008 durchgeführten Umfragen unter am LEADER Programm beteiligten Personen in Rumänien, Ungarn und Deutschland. Es zeigt sich, dass Netzwerke ein Schlüsselfaktor für die Implementierung ländlicher Entwicklungspolitik sind. Es spielt dabei nicht nur der erwartete Nutzen durch Erfahrungsaustausch und Partnerschaften eine Rolle, sondern auch soziale Kontrolle, welche als verdeckter Effekt von Netzwerken zu sehen ist.

Schlüsselwörter: Politik zur Entwicklung des Ländlichen Raums, LEADER, Europäisches Netzwerk für ländliche Entwicklung, Netzwerke, Rumänien

\footnotetext{
${ }^{1}$ The authors like to thank the German Academic Exchange Service (DAAD) for supporting the empirical fieldwork in Romania in 2008

${ }^{2}$ Leibniz Institute of Agricultural Development in Central and Eastern Europe (IAMO), Theodor-Lieser Str. 2, 06120 Halle (Saale), Germany (www.iamo.de). Corresponding author: Doris MARQUARDT; Email: marquardt@iamo.de
} 


\section{Introduction}

Setting up the European Network for Rural Development, which includes 27 National Networks for Rural Development, is a profound objective of the European Commission (EC) for the period 2007-2013 (2005/1698/EC, Article 67 and 68). Networking in the form of exchanging experience, or establishing partnerships as an instrument for supporting the effectiveness of European policies is not a novel idea. Due to its positive effects - as generally emphasised by many authors (Loriz-Hoffmann, 2008; Lückenkötter, 2001; Moseley, 2003; DVS, 2008) networking can be an important driver of rural development. European experience with networks started with LEADER (Liaison entre actions de développement de l'économie rurale) in 1991. The LEADER programme emphasises two types of networking: 1) networking among stakeholders in a specific region in the form of local action groups (LAGs) following the bottomup approach; and 2) networking among actors from different regions. Furthermore, organised networking through the establishment of the European and the National Rural Development Networks, respectively, has been mandatory for the member states since 2007.

This paper investigates three policy-relevant research questions: (1) What key factors are relevant for implementing rural development policies, particularly LEADER and the National Network for Rural Development in Romania? (2) What role do networks play for implementing LEADER in Romania? (3) What relevance does the establishment of the European Network for Rural Development have for relations among Romanian stakeholders on the one hand, and for integration of Romanian actors into transnational and European-wide network activities on the other hand?

Methodologically, the research questions are addressed by analysing results from 2008 surveys conducted among 39 potential Romanian LAGs, 38 German and 27 Hungarian LAGs, and among 33 Romanian Directorates for Agriculture and Rural Development (DARDs), and 13 experts, for instance from the Romanian Ministry of Agriculture, Forest and Rural Development (MAFRD). The questionnaires were adapted to the respective stakeholder group, but all referred to the Romanian LEADER programme. Qualitative and quantitative data were collected via e-mail. Furthermore, a detailed empirical case study was conducted face-to-face dealing with the specific social relationships of actors from two potential Romanian LAGs in Harghita County and those of other actors identified as being involved in the two potential LAGs' development by applying a snowball-sampling method (Scott 1991). In total 65 actors, of which 52 form the two potential LAGs, were interviewed using a semi-structured questionnaire.

The following section describes European experiences with partnerships, particularly in the framework of LEADER. After that, recent Romanian LEADER efforts are discussed and the establishment of the European and the National Networks for Rural Development is analysed. The paper concludes with a discussion of the relevance of European-wide networking for implementing rural development policies in Romania.

\section{Experiences with partnerships, LEADER and EU-wide 'networking'}

Networking can be understood as the interplay and co-action of information and experience exchange, and as cooperation and collaboration. In short, networking describes social relations among actors. ${ }^{3}$ As such, it is a feature of many policy measures within the European Union (EU) including, for instance, education in the Lifelong Learning Programme, or Twinning Projects. The development of networking activities in EU rural development policy is rooted in the LEADER programme.

\footnotetext{
${ }^{3}$ There is no generally applicable distinction between the terms 'networking' and 'partnership'. If a distinction is sought, one or more of the following criteria are usually applied: formality of relations (e.g. Moseley 2003), reciprocity of relations (e.g. Segert \& Zierke, 2004) and intensity of relations (e.g. 2000/C139/5). Accordingly, compared to networks, partnerships are more formal, more reciprocal and more intensive in terms of relations. This paper deals with institutionalised networks as well as informal partnerships. In this context, it seems enough to point out that in partnerships the members are aware of each other and directly linked while in networks the actors do not necessarily all know each other.
} 


\subsection{Main features of the LEADER programme}

The objective of LEADER is to advance the socio-economic development of rural regions. To this end, the LEADER instrument co-finances competitively selected regional development concepts of LAGs, which consist of public-private partnerships (PPPs). In addition, interregional and transnational collaborative projects between LAGs are supported. LEADER combines multiple notions, including a bottom-up approach that entails the participation of the local population, as well as integrated multi-sectoral regional and territorial development and innovation approaches.

After its initial implementation in 1991, LEADER evolved into LEADER II and then into LEADER+ which, in 2007, was transformed into one of the four major thematic axes of the rural development pillar (Pillar 2) of the Common Agricultural Policy (CAP). It thus became 'mainstreamed': LEADER is now an obligatory part of the Rural Development Programmes (RDPs) in the member states, and is funded under the European Agricultural Fund for Rural Development (EAFRD). With its integrated approach, LEADER acts as the overarching fourth axis to the priorities of the other three thematic axes of the EAFRD: 1) Improvement of the agricultural and forestry sector's competitiveness; 2) Improving the environment and countryside; and 3) Quality of life in rural areas and diversification of the rural economy. $(2005 / 1698 / E C)$.

\subsection{Experiences with partnerships and networking in Europe}

When reviewing the different periods of LEADER from 1991 to 2007-2013, the significance of partnerships and networking becomes evident. ${ }^{4}$ During this time, network activities have increased and gained relevance as a policy instrument. ${ }^{5}$ On the one hand, networking has been stimulated by EC funding. From 2000-2006, 1,153 European LAGs were financially supported through LEADER funds and active in 383 transnational and 1,130 cross-border partnerships (Török, 2008).On the other hand, these activities have been embraced by rural people when they discovered the positive effects of partnerships and networking.

Indeed, partnerships and networking have the potential to strengthen the social and human capital of LAGs. But establishing and reinforcing partnerships requires trust and resources particularly time - and pro-active measures. Thus, entering into a partnership goes hand in hand with cost-benefit considerations. Box 1 provides more details on partnerships of the Hungarian and German LAGs studied.

Detecting network structures and coordination patterns becomes increasingly important when many actors are involved. For this, even prior to the current funding period, formal and informal LEADER networks of various relational dimensions were established: most EU member states had a network unit at the national level. At the European level, the EU LEADER+ Contact Point was established. The aim of these institutions was to spread information among the LAGs and to facilitate the search for actors with similar interests and the exchange of experience among different LAGs, as well as assisting those LAGs wishing to cooperate with other actors. With the termination of the last LEADER period in May 2008, the Contact Point in Brussels and most of the national network units ceased operations (Courades, 2008a). Thereafter, network units were established or re-established and assigned new tasks in all member states according to the new EU-wide rules on the obligatory establishment and coordination of the networks for rural development in the period 2007-2013.

\footnotetext{
${ }^{4}$ At first, only the establishment of partnerships within single regions was formally supported by EU funds. At the same time, many LAGs informally developed relations with other LAGs to exchange experiences or to conduct joint projects. In the next period, cross-border cooperation between LAGs became a facultative support objective. In the subsequent period, cross-border and transnational partnerships were financially supported. Furthermore, in some countries it is considered positive in the selection process if LAGs include the establishment of partnerships in their development strategies.

${ }^{5}$ Currently, two kinds of partnerships can be financially supported within LEADER: a) formally founded intra-regional partnerships (LAGs) between public and private actors, and b) interregional partnerships in which two or more LAGs (or similar groups) formally cooperate. For becoming financially supported, such cooperation projects have to go beyond the exchange of information, which is understood as "networking" according to the LEADER terminology (cp. 2000/C 139/5). Alongside those partnerships funded within LEADER, there are several kinds of formal and informal intra-regional and extra-regional partnerships between LAGs and other actors.
} 
In this study, the "partnership culture" of LAGs from both Germany and the new member state Hungary was analysed. The results show that, on average, LAGs from both countries have 2.2 partnerships, whereas the number of partner regions does not correlate with the period a LAG has existed.

Though less experienced with LEADER, Hungarian LAGs are not less active in establishing partnerships and are already well integrated into the European LEADER network. Most often, the partners of the LAGs are from the same country (Germany $52 \%$, Hungary $61 \%$ ). There are more relations to LAGs in the EU-15 (Germany 34\%, Hungary 22\%) than to regions in the new member states (EU-10). Generally, Hungarian LAGs have more partnerships in the EU-10 $(17 \%)$ than do German ones (14\% of all partnerships). A good number of the consulted LAGs (52\% Germany, 60\% Hungary) have partnerships with other regions independent of LEADER funds. These partnerships are mostly informal. $74 \%$ of the Hungarian LAGs and $52 \%$ of the German LAGs are interested in additional partnerships. Less than half of the LAGs prefer a partner to be from a certain area. In such cases, mostly neighbouring countries were mentioned or, in the case of the Hungarian LAGs, old member states were preferred partners.

Box 1. Partnerships and cooperation of Hungarian and German LAGs

\section{The LEADER Programme in Romania}

Below, the implementation of the LEADER programme in Romania is described from its initial announcement in mid-2006 through to mid-2008. We are specifically interested in how networks evolve and are used during this process. Our database offers recent and detailed insights with regard to these issues. Looking at Romania allows investigation of the relevance of networks for potential LAGs in a post-socialist context, where LEADER-like policies are unknown and have to be established completely from scratch.

\subsection{Implementing LEADER in Romania}

In Romania, people's mentality and policy perception are heavily influenced by four decades of socialism. During that era, regional policy measures, as well as local institutions, were virtually non-existent (Mandl et al. 2007). A process of decentralisation was first induced when EU membership was anticipated. In the pre-accession period 2000-2006, legally registered microregion associations were set up in many Romanian counties (NRDP 2008). Micro-region associations are inter-communal associations which jointly develop and co-finance projects. As such, one of their main purposes was and is to access national and EU funds. Additionally, a few informally established local initiative groups (LIGs) evolved consisting of private and public actors. The LIGs' creation was often stimulated by (pilot) projects, which in turn had been initiated by supra-regional, non-governmental organisations (NGOs) that support civil society, community and rural development (e.g. the Regional Centre for Sustainable Rural Development in Constantza or the Civitas foundation). Such organisations are instrumental facilitating access to national ${ }^{6}$ and EU funds by offering technical assistance to local actors. However, the projects undertaken rarely applied an integrated approach and many LIGs dissolved after their project came to an end.

At the administrative level, initial experience in rural development policy was gained when implementing the EU's pre-accession instrument, the Special Accession Programme for Agriculture and Rural Development (SAPARD). SAPARD started in 1999 (NRDP 2008). This implies that LEADER, with its bottom-up and networking approach, was completely new and unfamiliar, not only for the administration but for the potential beneficiaries too.

The implementation of LEADER in Romania is barely documented. However, it is clear that LEADER is not evolving as planned. According to the programme guidelines, LEADER should have started in February 2009, when the original deadline for applications passed. However, up

\footnotetext{
${ }^{6}$ One noteworthy national programme is the 'Social Development Fund', which started in 1999. It is a long-running programme with national coverage that has provided village infrastructure projects in the poorest communities. Other programmes with a similar approach exist, e.g. the 'Rural Development Project' with the World Bank as main donor.
} 
until August 2009 at least, there has not even been a call for applications and the planned competitive selection of the first 40 LAGs has not taken place.

Preparations for putting LEADER into action started with an EU Twinning Project (RO 2004 IB AG 05) involving French, German and Hungarian partners. In mid-2006 the programme was first announced in Romania. Half a year later, the pre-selection of 121 regions followed. Subsequently, representatives (LEADER-animators) from these regions participated in LEADER seminars. The decisive criteria for the pre-selection of LAGs were easy to identify: the region's classification as a rural area, and a minimum size measured in terms of the number of inhabitants (for details see NRDP 2008). In addition to this, the potential LAGs of these regions "only" had to demonstrate that they possessed the potential to function as a group of different types of partners and that they had the necessary administrative, financial and human capacities. Compliance with the participatory approach of LEADER was not directly considered in the selection process.

Of the 39 potential LAGs in our sample, $72 \%$ emerged from micro-region associations. Only a small share $(18 \%)$ of the potential LAGs were not initiated by administrative actors such as mayors or public utilities, but started as bottom-up initiatives established, for instance, by commercial actors or NGOs. The remaining $10 \%$ were initiatives in a mixed constellation of private and public actors, or their makeup remained unclear.

\subsection{Key players in the LEADER programme - What happened in Romania?}

This section looks at key players involved in implementing the LEADER programme between 2006 and 2009. These are the potential LAGs (i.e. the potential beneficiaries) and the programme agencies on the administrative side. For both of these, networking could be a very important factor for successful sharing of information and for preparing or supporting initiatives.

\section{Development of potential LAGs}

In early 2008, just one year after the pre-selection process, some of the pre-selected LAGs had already dissolved while some newcomers had emerged. Marked differences in ability to comply with eligibility criteria stipulated in the programme may have been one reason for this. It emerged, however, that elaborating regional development strategies was one of the main difficulties: only $28 \%$ of the surveyed potential LAGs had set out a regional development concept at the beginning of 2008. Problems occurred due to lack of experience and/or human resources. Some micro-region associations employ a regional manager to put things right. Also, networking turned out to be an advantage. Romanian and foreign organisations offer assistance, mostly by organising LEADER seminars, but sometimes also through direct support with elaborating regional development concepts. These include, for example, the Romanian Civitas Foundation, the German organisation InWent, and the Hungarian LEADER Centre and foreign LAGs. One general problem is that the LAG actors feel overextended by the demands of LEADER. More than half of the local actors would prefer pre-defined measures instead of having to elaborate a concept on their own. Being as pro-active as required clearly presents difficulties.

Furthermore, potential LAGs have to deal with initiating formal PPPs, i.e. adopting a legal form. These PPPs should include financially strong partners who are able to co-finance project activities. Although in many LAGs the first initiatives in the field of regional development had begun prior to 2006 (Fig 1), three-quarters of the potential LAGs had no legal form until 2008. Moreover, the micro-region associations face challenges in terms of integrating commercial and/or societal partners into the contracted network of communes. One reason for this is that accepting a participatory approach, i.e., sharing decision-making with local associations or other private actors, seems difficult for many mayors. ${ }^{7}$ LAGs that were established in a bottom-up manner are often more diverse in their composition. However, they too have problems as

\footnotetext{
${ }^{7}$ Mayors prefer to collaborate with public utilities, which are subject to a certain degree of social control and have educated staff and administrative capacities (Marquardt et al., 2009b). However, the extent to which public partners can participate in a LAG is limited by programme guidelines. Thus, on the one hand, the mayors have to accept a participatory approach at least on paper. On the other hand, the realisation of a participatory approach is not a matter of course, because often people brought up under socialism find it difficult to act democratically within such an approach (Heller 1999; World Bank 2008).
} 
regards entering into a contract and adopting a legal form. Both antipathy to collective actions and mistrust vis-à-vis formal institutions are (still) strong in Romania and explain the problems in building formal partnerships. Indeed, a general problem, for example, perceived by $83 \%$ of the surveyed DARDs concerns collaboration between public and private actors. According to these, the rural environment in Romania is characterised by a low level of trust in formal affairs and institutions (see also Mandl et al. 2007).

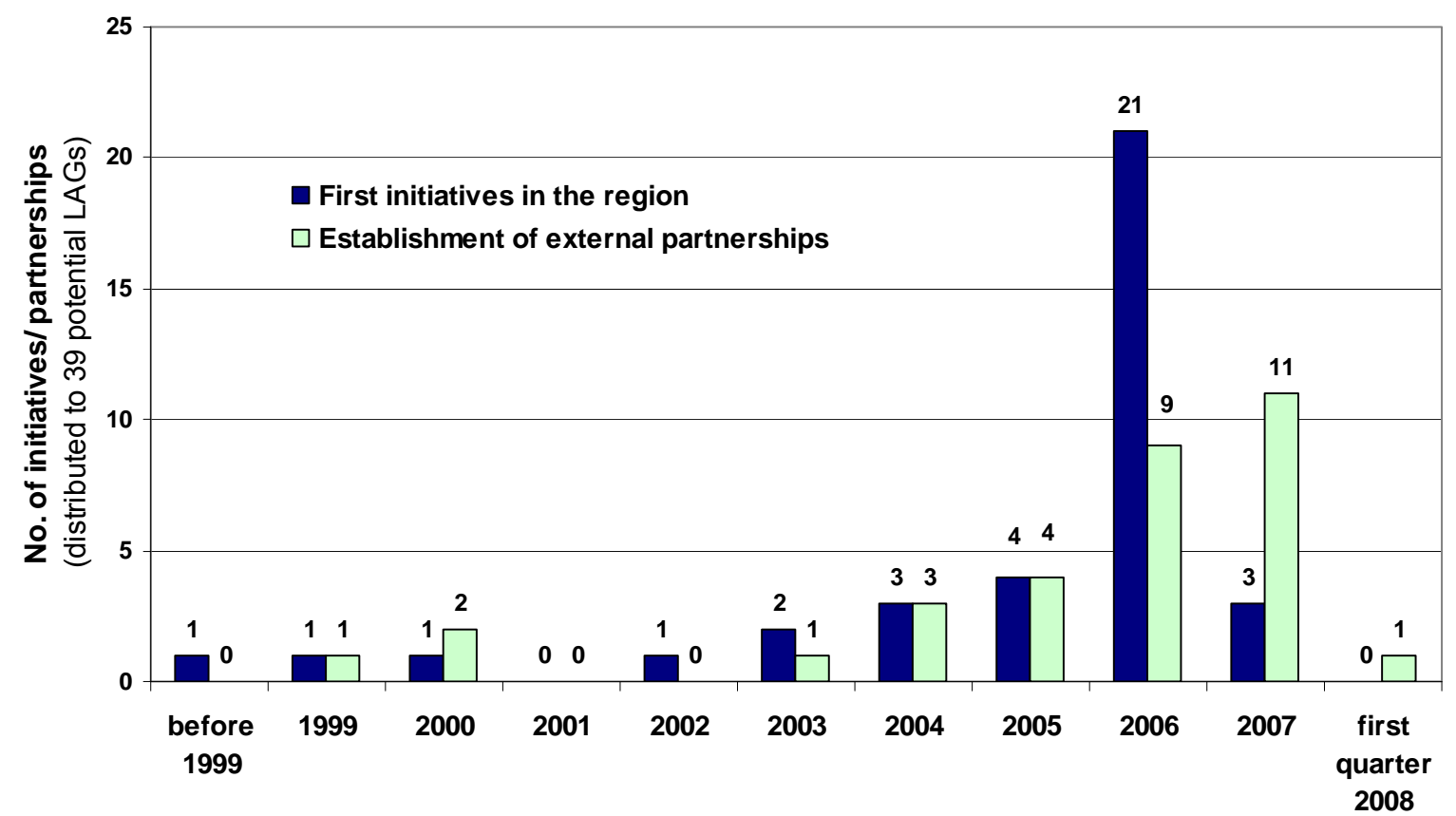

Note: Of the 39 potential LAGs, 19 have extra-regional partnerships. These 19 LAGs have an average of 2.6 partnerships. For 16 of the partnerships mentioned, the time of establishment could not be specified.

Fig 1. First regional development initiatives and extra-regional partnerships by potential Romanian LAGs since 1999. Source: own survey 2008).

Our case study findings highlight that external actors, particularly well-known supra-regional organisations, can function as mediators between the different parties involved. Often even their sheer presence can be conducive to 'guaranteeing' that the participatory LEADER approach is satisfied. However, in the longer term, the building up of trust among the partners and the subject of the contract can only be indirectly supported by external actors: they can set examples of good practice in LEADER partnerships and they can stimulate networking in the regions.

Surprisingly, half of the potential LAGs had already formed partnerships, albeit informal ones, with external actors before being formally established and before partnerships were financially supported through LEADER funds. Contact was made mostly through seminars or a targetoriented search. Partnerships usually started shortly after the first initiatives in regional development emerged in the respective regions. Fig 1 shows that a first wave of intra-regional relationships peaked in 2006. This was followed by a second wave of external partnerships with a lag of one year. The potential LAGs apparently deem external partnerships as very promising for their development. Fig 2 illustrates that about half of the partners are of Romanian origin.

Many partners of the 39 potential LAGs researched are from the EU-15, mainly from Germany. Hungary contributes $12 \%$ of the partners ${ }^{8}$; other new member states play a minor role in the partnership activities of the potential Romanian LAGs. Most of their partners are represented by organisations (Fig 2). Partnerships with organisations are often one-sided in the sense that the Romanian counterparts are supported, while they are unable to bring in something of equal value. While such one-sided partnerships would hardly be accepted by other LAGs or trade

\footnotetext{
${ }^{8}$ The high share of Hungarian partners is due to a) Hungary being a neighbouring country, which compared to Bulgaria, for example, is experienced in LEADER; b) strong cultural relationships with some Romanian regions with Hungarian minorities (see Box 2); and 3) Hungarian actors, supported by the Hungarian LEADER Centre, are generally very active in establishing partnerships.
} 
partners, for instance, which strive for a win-win partnership, many organizations named "partner", mostly civil or environmental ones, are involved due to their stated mandates to support regional development.

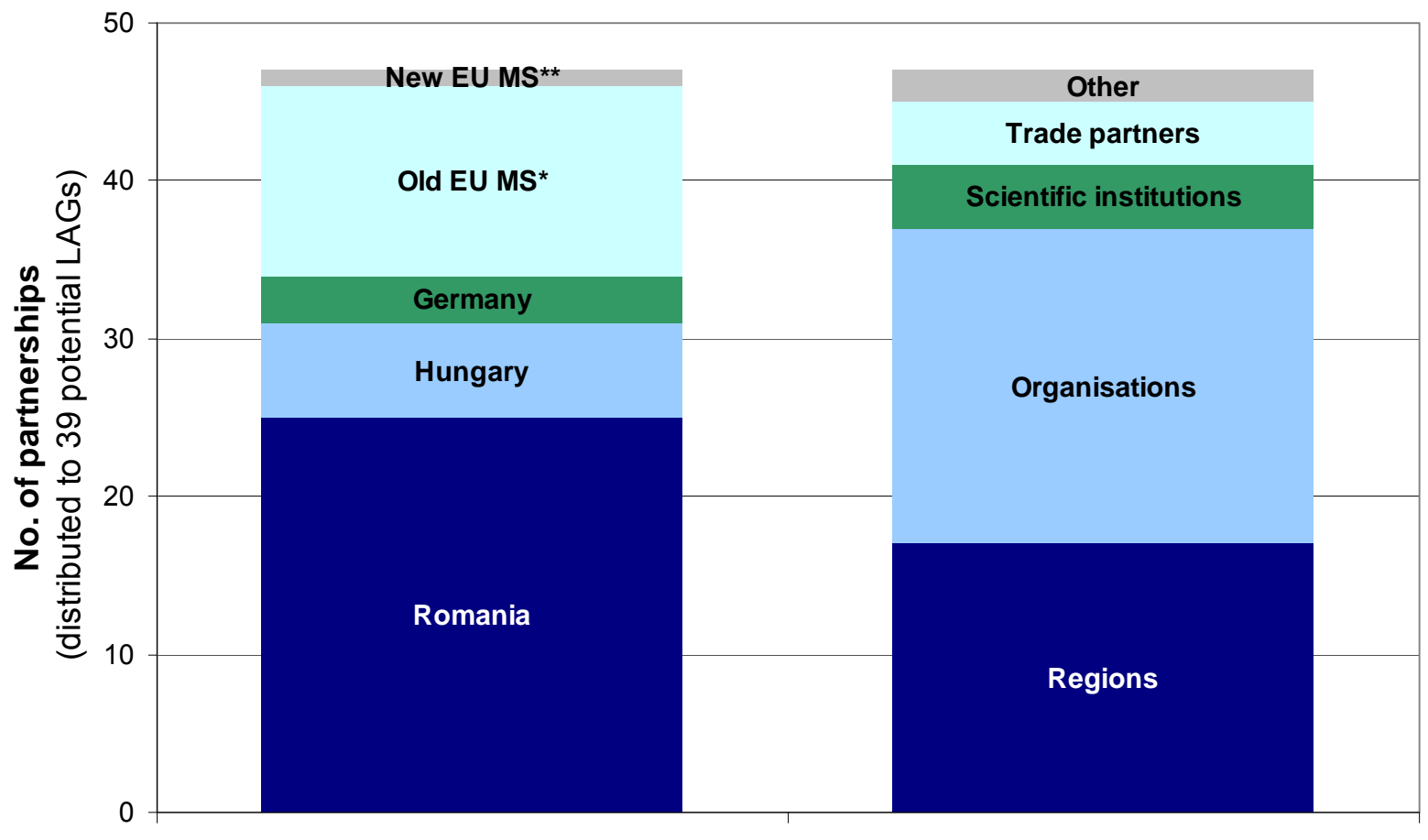

Origin of the partners

Kind of partners

Note: $M S=$ Member states; * without Germany; ** without Hungary.

For 2 of the surveyed 49 partnerships, the type of partner could not be specified, this results in $n=47$.

Fig 2. Nature and origin of partners of the Romanian potential LAGs. Source: own survey (2008).

\section{The role of the programme agencies}

Understanding the implementation of LEADER in Romania is not possible without considering the programme agencies themselves. They are represented by the General Directorate for Rural Development at national level and the DARDs at county level. Employees of the programme agencies at county level were trained in LEADER parallel to the pre-selected LAGs. We find, however, that one-third of the trained employees still regard the programme as difficult to comprehend and cannot imagine how LEADER will work in practice. In 2007 and 2008 one of the main tasks of the DARDs was to disseminate information about rural development measures, including LEADER. The most effective means of spreading information were targeted information events, their main advantage being that people could ask questions or discuss issues that confused them. However, because the main interest of the audience mostly farmers - is usually in direct payments and measures of Axis 1 and Axis 3 of Pillar 2, LEADER is often inadequately addressed or not at all. This also explains why mayors (despite being in contact with the programme agencies) often heard about LEADER through the traditionally influential County Councils. Additionally, foreign actors are important sources of information about LEADER for local actors, as well as for the personnel of the programme agencies. Nevertheless, it appears that, overall, people in rural areas (i.e., the potential beneficiaries) are not sufficiently informed about the possibilities of how to take advantage of LEADER, because the agricultural administration does not effectively disseminate information. As mentioned above, most programme agencies lack qualified staff, which is a general problem in the Romanian agricultural administration (Labar et al., 2009; Marquardt et al., 2009a).

From 2007-2008, no further LEADER-specific activities were carried out by the programme agencies. That means that there was also no regular or concerted contact with the pre-selected LAGs. ${ }^{9}$ Instead, the potential beneficiaries were faced with several changes to the programme

\footnotetext{
${ }^{9}$ This circumstance calls into question the following statement in the Romanian RDP (NRDP 2008): 'The potential LAGs selected for training maintain permanent contact with the Ministry and the Agricultural Directorates for Rural
} 
guidelines: among other things, the criteria relevant for the demarcation of the LEADER regions were redefined. In addition, the first measure of the LEADER axis (Measure 431.1), intended to provide financial support for building up capacities and elaborating strategies to all potential beneficiaries (even those who were not selected for training in 2006), was delayed until August 2009.

These circumstances may explain why some potential LAGs lost interest in participating in LEADER. There are suggestions that some of them stopped believing in the capability of the programme agencies and even in the realisation of the programme in Romania. Strengthening the capacity of the programme agencies is therefore important for four reasons. First, there is a need for further target-group-oriented information spreading, which is a core task of the programme agencies. Second, relationships of trust have to be established. Third, potential LAGs that are inexperienced and cannot afford a regional manager must be given professional advice to enable them to comply with the criteria for participation in LEADER. Fourth, the position of the programme agencies in the implementation procedure must be strengthened to ensure that the influence of political institutions such as the County Councils is lessened.

As mentioned above, the County Councils, because of their close relationship with the mayors, are powerful and sometimes act in competition with the programme agencies. Not only can they spread information about LEADER in any manner they like (which may have positive or negative effects), but they can also steer the competition of the potential LAGs by distributing financial resources to favoured communes. This political influence was reported to discourage businessmen from entering into PPPs. ${ }^{10}$ The mayors themselves usually play a supportive role, especially when they have established a relationship of trust with their local people. We find that their behaviour can clearly facilitate acceptance of the bottom-up notion: if mayors want and accept the participatory approach, they can be important players for promoting LEADER and motivating farmers (and others) to become active in rural development. Furthermore, by amplifying the contact between agricultural administration and the farmers, they can support the absorption of funds and the effectiveness of other rural development measures.

\subsection{Will networkers benefit more from LEADER in Romania?}

Establishing a formal partnership and preparing an application takes time. Obviously, those who are able to organise themselves (and others), and through their networks are quickest in familiarising themselves with the funding possibilities of LEADER may benefit most. Those who can rely on external support or have already taken part in other EU programmes can draw on these experiences and networks and will therefore be more competitive.

Organisational structures and administrative capacities are especially important for being capable of complying with the formal criteria of the LEADER guidelines. Micro-region associations, due to their communal origin, have an advantage here. However, their existing structures may become a handicap when it comes to implementing the mandatory participatory and bottom-up approach of LEADER. Social networks that have evolved endogenously are more competitive in terms of these LEADER principles and have a higher chance of working together in the longer term. Such potential LAGs may also be more resilient when delays in programme implementation or other problems occur. However, despite their LEADER-like structure, many of these potential LAGs may in the end prove uncompetitive because they cannot comply with other selection criteria, e.g. proving their administrative capacities or elaborating regional development strategies in accordance with the programme guidelines.

Although LEADER is a rural development programme, farmers are a minority among the actors involved. Hence, although they make up the major population group in Romanian rural areas, farmers will only profit from LEADER if the LAG in their region follows an integrated approach that includes agricultural concerns. Perhaps farmers - more than other population groups - still

Development'. This statement was also quoted and seemingly accepted by Jean-Michel Courades of the European Commission in the Member States Reports (Courades, 2008b).

${ }^{10}$ For instance, the success of projects in the tourism sector is influenced by many factors that can potentially be influenced by policy-makers, e.g. infrastructure. Moreover, as a LEADER project is intended to last longer than one electoral term, businessmen are afraid that under a new power coalition, they could lose the support of the County Council. 
stick with their "mentality, which is the result of 40 years of socialism" (Heller 1999, p. 108). Networking and participatory, bottom-up approaches may seem alien to them and they are frequently not pro-active enough. As a matter of fact, those involved in LEADER are mostly mayors, employees of public institutions, NGOs or businessmen - possibly because it is easier for them to establish networks.

In particular, these groups may be better endowed with possibilities for establishing far-reaching ties for gathering information from external actors such as foreign LAGs, which have proved to be important for the successful start of an initiative (see above). But strong local ties, which allow social control, are also important. In tight social networks, trust may increase among group members because of the inherent social control. Thus, social control influences the behaviour of the members because compliance with norms is expected. ${ }^{11}$

In the end, a lot depends on the selection committee: they will decide which aspects are assessed as important and in doing so influence the selection of beneficiaries. Also, even if the committee for the selection of the LAGs seems to represent a balanced constellation of central and local authorities, of academics and other organisations (NRDP 2008), it is obvious that political influence will be exerted on the choice of LAGs. For instance, special rules fixed in the National Rural Development Programme (NRDP) (NRDP 2008, p. 317) favour the potential LAG of the Danube Delta by allowing it a smaller territory (covering 5,000 instead of 10,000 inhabitants). ${ }^{12}$ Other potential LAGs are expected to disband because they cannot reach the requested critical mass. Again, we see that those who are well-connected may derive the most advantage.

\section{Does networking need policy support?}

The previous sections highlighted that network activities can exert positive effects. Nevertheless, it also became evident that partnerships and networking do not necessarily run themselves due to the need of personal effort and resources. Hence, if networking should be used as a target-oriented instrument, stimulating and supporting measures are required. Different instrumental effects of networking should be considered: (1) the economic output of relations as well as flows of information are important initial factors for further network activities (Box 2) and relevant for triggering processes such as the implementation of LEADER in Romania. (2) Information brokering and experience transfer seem to be particularly fruitful if they build upon interlinked ties, meaning that the addressees actively receive or even seek information ${ }^{13}$ and transfer information. (3) Through reciprocal ties feedback can be provided, and this enhances (regional) development processes (Stahl \& Schreiber, 2003).

Social interaction should be at the heart of any networking measure because - according to Johnson (1992) - it advances learning processes. A good example of a measure design which builds upon the effect of social interactions is a mentoring programme that was started by the Hungarian LEADER Centre in October 2008. This programme aims at imparting LEADER approaches to Romanian counterparts. Mentors of Hungarian LAGs have to present their newly-gained LEADER experiences and assist Romanian micro-region associations by setting out the basic requirements for LEADER-like development of the respective regions. The analysis of our dataset showed furthermore that personal communication is a key factor for establishing trust within and among different groups. However, for maintaining regular contacts, the internet is the most important means of staying in touch for the LAGs studied $(75 \%$ of the German and $67 \%$ of the Hungarian LAGs maintain contact with their partners via e-mail). Thus,

\footnotetext{
11 The case study showed that social control in remote villages, where everyone knows each other and people are used to relying on mutual aid and interacting with each other, results in poorer persons being accepted within the potential LAG despite being unable to contribute financially to a project.

${ }^{12}$ No adequate reason is given for this. The Danube Delta is described in the NRDP (2008) as an area of high natural value with a low population density $\left(28\right.$ inhabitants $\left./ \mathrm{km}^{2}\right)$. However, such criteria would be applicable to many regions in Romania where $7.8 \%$ of the country is under protection and $17.8 \%$ are designated Natura 2000 areas. Reaching the standard critical mass in terms of number of inhabitants would not exclude the communes of the Danube Delta from participating in LEADER - it would just be more challenging to collaborate with a higher number of communes. The influence of various lobbyists is also reported by Redmann (2008).

${ }^{13}$ This is described by Nelson \& Farrington (1994) as bilateral exchange of information.
} 
the importance of modern communication technologies for maintaining relationships should be considered in the programmes.

Existing contacts with Romania. From our sample, $8 \%$ of the German and $14 \%$ of the Hungarian LAGs have partnerships with Romanian actors. Aside from two potential LAGs, most of the Romanian partners are organisations (e.g. Tourism Association, Forestry School). Most partnerships were established in 2007. Several differences between the characteristics of the German contacts and those of Hungarian LAGs to Romanian actors may be observed: 1) When finding partners, the German LAGs stated that they got to know the Romanian actors by personal contacts or by collaborating with institutions. The Hungarian LAGs found their Romanian partners by target-oriented search or during seminars. 2) In terms of cultural relations, all partners of the Hungarian LAGs are from parts of Romania with strong Hungarian minority groups. 3) The hitherto existing results of the partnerships in the case of the German LAGs were personal relationships and a better understanding of the other culture. Contrary to the Hungarian LAGs, no concrete joint projects were mentioned. Furthermore, the Hungarian LAGs reported a lively exchange of information and experiences and reciprocal training visits.

Reasons for and against establishing partnerships with Romanian actors. The German and Hungarian LAGs without Romanian contacts were asked about their reasons: $86 \%$ of German LAGs (but none of the Hungarian LAGs) had simply not yet considered the possibility of building up contacts with the new member state. However, only $6 \%$ of the German and $20 \%$ of the Hungarian LAGs said they were not interested in such contacts. No country-specific reasons with regard to Romania were mentioned - for instance, having received negative reports about Romanian actors or scepticism towards a foreign culture. However, a good quarter of the LAGs see the language barrier or the geographical distance as a problem. Many mention deficits in money and/or time as a general problem with regard to establishing and maintaining contacts. Hungarian LAGs in particular noted that they are concerned with the management of their own LAG and with elaborating regional development concepts.

Nonetheless, $68 \%$ of the German LAGs and all of the Hungarian LAGs could envisage a (further) partnership with Romanian counterparts. This was not least because, by establishing personal relations with external actors, the cohesion of one's own LAG is increased, awareness and pride in the region are strengthened and the image of the region is enhanced (see also Duguet, 2008). However, the majority of the LAGs consulted stated that funds were a precondition for such activities (Fig 3).

Box 2. Partnerships of German and Hungarian LAGs with Romanian actors.

Instruments should specifically target the establishment of ties and networks that are otherwise too costly for the actors involved. There is evidence that interest in establishing partnerships depends on the availability of funding (Fig 3). Fig 3 and Box 2 describe the situation of existing and possible contacts between German and Hungarian LAGs with Romanian counterparts. While our results support the notion that, overall, the Romanian LEADER programme in its initial phase greatly benefits from international partnerships, the question arises whether such partnerships are a good selection criterion for LAGs. Interestingly, many partnerships of German LAGs (not only with Romanian actors) were established only shortly before the respective application deadlines. Time will show whether those relations develop into real partnerships or remain artificially-staged collaborations. 


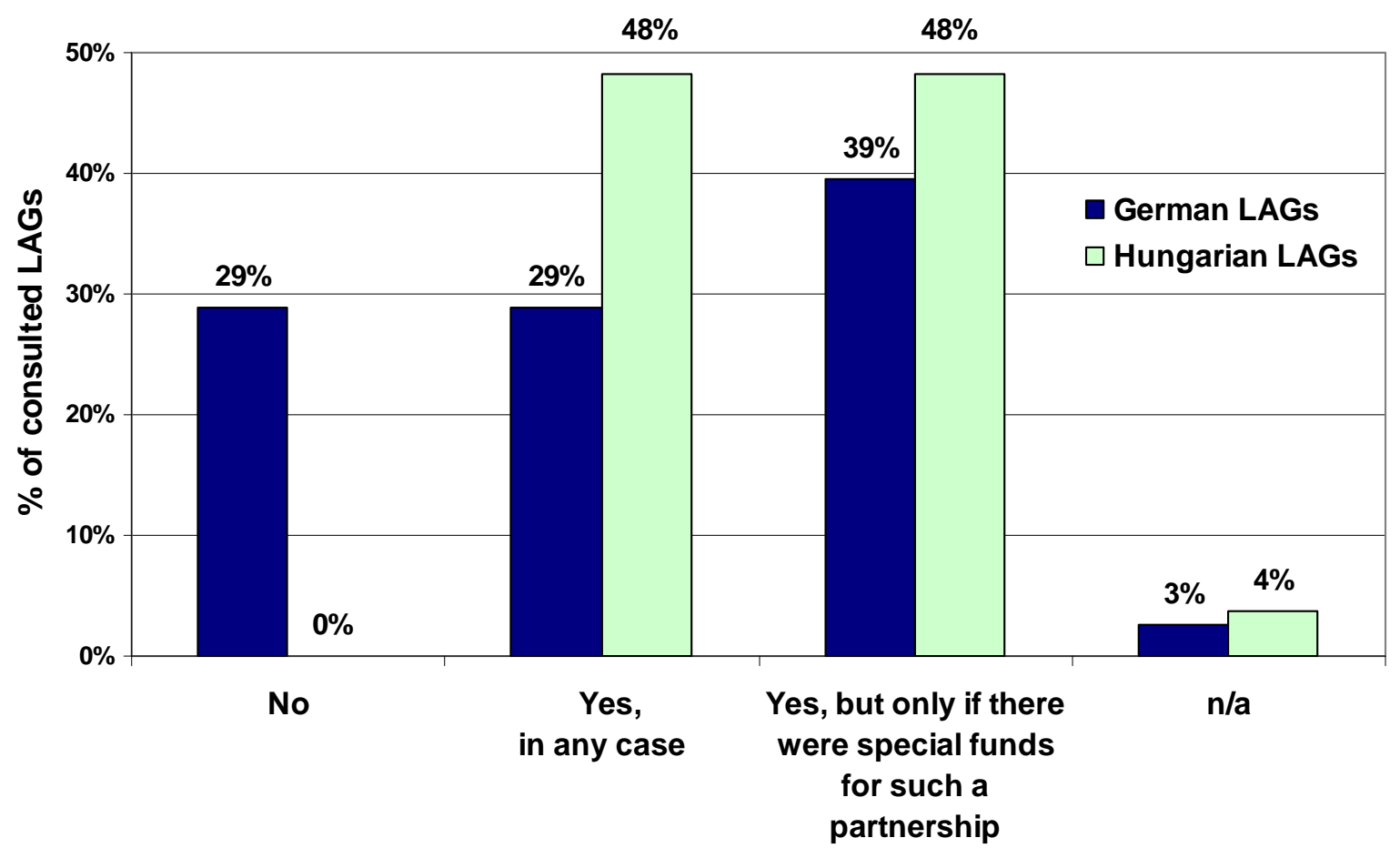

Note: Sample $=38$ German and 27 Hungarian LAGs.

Fig 3. Interest of German and Hungarian LAGs in (further) partnerships with Romanian actors. Source: own survey (2008).

\section{Networks for Rural Development in Europe from 2007-2013}

Besides incentives that address local actors, the establishment of networks can also be stimulated by regulations. This is the case for the national programme agencies that are responsible for implementing EAFRD measures. For the period 2007-2013 the EU demands the mandatory establishment of so called European and national 'Networks for Rural Development'. Below, after a brief introduction, we focus on potential effects on rural development in Romania resulting from the establishment of these networks.

\subsection{The concepts of the European and National Networks for Rural Development}

In the most recent funding period, 2007-2013, Articles 67 and 68 of the EAFRD Regulation provide for the establishment of institutionalised national networks that are connected to the European Network for Rural Development. Establishing such networks for rural development enables building upon the experiences of the LEADER programme. In some member states national network units were established to serve LEADER activities alongside the general EU LEADER+ Contact Point for LAGs. However, the current period differs in some aspects from the networks' activities within LEADER in previous periods: (1) the networks in the period 20072013 have a broader spectrum of rural development topics (EC 2006); the new networks are expected to deal with all four thematic axes of the rural development pillar of CAP. (2) The networks not only include LAGs but also organisations (e.g. foundations, NGOs), as well as ministries and subordinated agencies. (3) Establishing the National Networks for Rural Development is mandatory for the member states.

The main tasks the European and National Networks for Rural Development are (a) the preparation and transfer of information about approved measures and good practice in the field of rural development; (b) collecting data about development in the member states and third countries; and (c) the organisation of training. Furthermore, there is the possibility of (d) 'direct support' for all stakeholders (Jacobs, 2008). This last task targets LAGs, foundations and agencies, for instance by providing assistance with implementing EU policies for rural development and establishing transnational partnerships. Hence, the European network should provide "real incentives for achieving the objectives established within the framework of the EC 
strategic guidelines [2006/144/EC]" (Sousa Uva, 2008), which are operationalised in the rural development programmes with their four thematic axes.

The European Network for Rural Development was to consist of two organisational components; the first is the Evaluation Expert Network, which has been in place since the first half of 2008. The appointed experts will monitor and evaluate rural development programmes. Second, a Coordination Committee was established, to which, among others, two representatives of all member states belong. The first meeting of the Coordination Committee was held on $1^{\text {st }}$ October 2008; two weeks later the European Network was declared operational.

The European Network is supposed to be closely interlinked with the national networks (Courades 2007). The national rural networks, which are mostly associated with the Ministry of Agriculture, were to be established by the end of 2008. Also by this time an action plan was supposed to have been in place (2008/168/EC). For establishing and coordinating the networks, the member states can draw on technical assistance funds (Article 68 EAFRD regulation). In early 2009 two-thirds of the planned networks had established a steering committee (Law 2009). The continued development of the European and the national networks will depend heavily on the members themselves, because - as the description for the Romanian one states "the actors represent the Network, and the success of the Network depends greatly upon their willingness to contribute actively to the process of sharing ideas" (NRDP 2008).

Time will show if the European Network for Rural Development and the national rural networks will fulfil their function as instruments for supporting the realisation of rural development policies. Among other things, the linkage between the national network units and the European network presents a challenge, as stakeholders with different interests and backgrounds have to be integrated along all thematic axes and a vertical dialogue (top-down versus bottom-up approach) ensured (Law, 2009). The success or failure of the networks also depends on whether the member states see their establishment only as an obligation they have to fulfil or they invest more effort because they see genuine benefits.

\subsection{What is to be expected of the Romanian National Network for Rural Development?}

In Romania, organised networking among stakeholders who are active in the field of rural development has thus far been only rudimentary. One of the few noteworthy organisations is the RuralNet - an umbrella organisation of 26 foundations and associations, e.g. the Center of Rural Assistance and the Carpathian Foundation, which are engaged in developing civil society. The RuralNet is also mentioned alongside the national programme agency as a contact point for requests regarding LEADER in Romania on the homepage of the former EU LEADER+ Contact Point. However, this organisation is relatively unknown in Romania.

Due to the lack of experience in the field, establishing the National Network for Rural Development is a challenge for the Romanian actors. But in contrast to LEADER, faster progress is observed. The Romanian way of developing the National Network for Rural Development is seen as notable by some (Dower, 2007): the DARDs, the subordinated programme agencies, first identified the 'most representative actors involved in rural development at the level of each county'. These actors were then asked to express their interest in participating in establishing the National Network for Rural Development. This procedure enabled collection of suggestions for the advancement of the National Network for Rural Development. Meanwhile, the National Network for Rural Development accounts for 363 members, among them potential LAGs, associations and ministries (NRDP 2008). In addition, the 2008 surveys of the DARDs and potential LAGs showed that the local actors have a great interest in getting involved in the National Network for Rural Development procedures.

Although Romanian actors cannot draw on networking experience within LEADER, positive synergy effects are expected: through the National Network for Rural Development, constructive feedback from potential beneficiaries of rural development measures could flow back to the programme agencies (Marquardt et al., 2009a). Furthermore, the National Network for Rural Development can contribute to the establishment of links, e.g. between scientific institutions and agricultural businesses. The challenge will be to involve not only the key players, like the abovementioned organisations and potential LAGs, which are already present in the rural development arena. Instead, every endeavour should be made to induce a spill-over effect and 
attract new actors. Hence, implementing the Romanian National Network for Rural Development could, as suggested by Rusu (2008) in a very optimistic and (over)confident way, have the effect of providing the people from rural areas with representativeness. They would then be acting as partners for the national government and the ministry by identifying rural development priorities, as well as increasing participation in the decision-making and monitoring processes of the NRDP. However, for this the roles and voices of the different stakeholders have to change significantly, considering that the drafting of the NRDP is reported to be a predominantly exclusive and top-down process (Redmann 2008).

In this context it should also be mentioned that involvement of farmers, as in the case of LEADER, is low. Since 1990, there have been two attempts to construct a professional National Union of Romanian Farmers at the behest of the Ministry of Agriculture. Both attempts to involve those farmers with good development potential have failed (Stewart 1998). On the other hand, attempts by farmers' associations to get involved in writing the political agenda for implementing the CAP in Romania have failed, too. For instance, the MAFRD excluded members of its 'Social Dialogue Committee'14 from certain discussions. This applies to representatives of the National Federation of Farmers' Trade Unions, Agrostar, and of the National Federation of the Food Industry Trade Unions, who were all barred from the negotiations on the budget for 2008 (Ciutacu, 2008). These examples show vividly that the civil voice in agricultural and rural development policies is still very limited.

The National Network for Rural Development is also supposed to promote transparency and continuity. Due to unclear responsibilities, programme schedules and decisions the transparency of rural development measures is severely constricted. As mentioned above, at a subordinate level, the County Councils are sought as contact partners for LEADER instead of the responsible programme agencies. At the national level, turnover of professional staff in the departments of the ministry is high, causing a shortage of experts and a lack of continuity in the programmes, ${ }^{15}$ which is needed to create confidence among (potential) beneficiaries. The National Network for Rural Development could contribute to tackling these obstacles by bringing relevant stakeholders together.

\subsection{The relevance of EU-wide networking and the integration of Romanian actors}

Despite external assistance, Romanian actors still have an outsider position in rural networking compared to other EU member states. One reason for this is certainly that the LEADER programme is still not up and running. However, networking and partnership building can occur independently of LEADER, and the example of Hungary shows that embeddedness in EU-wide networks does not depend solely on the duration of EU membership (Box 1), but rather on the willingness of actors to get involved. Clearly, the Romanian actors need to gain experience, and at the moment they are mostly concerned with building up capacities for putting forward their own LAGs. As we showed above, it is in any case important and useful for stakeholders at all levels to get involved and develop reciprocal ties which help to integrate them in a network.

Key factors for successful networking are initiative and a pro-active approach. As described in Box 2 above, actors in other EU countries tend not to consider Romanian actors as potential partners. Raising their public profile is therefore essential. So far, however, the Romanian General Directorate for Rural Development has been rather reserved as regards promoting international contacts; they withdrew from activities such as the Euregia 2008 congress in Leipzig, Germany, and for a long time Romania was not present on the homepage of the EU LEADER+ Contact Point.

As described in the LEADER context, networking activities suffer if the actors do not trust each other. Opening towards and integration with European partners could have a positive effect on

\footnotetext{
14 The Social Dialogue Committees are created in order to foster dialogue between the social partners at European level. Their organisations jointly submit to the European Commission a request to participate in social dialogue at European level.

15 Since the drafting of the NRDP commenced, there has been a high turnover of Ministers of Agriculture and associated counsellors and staff. Inevitably, the huge budget for rural development measures attracted a great deal of political interest, and over a two-year timeframe there were a total of six ministers and some significant corruption charges. Each minister changed the political agenda (Redmann 2008).
} 
Romanian internal networks by increasing publicity and transparency, and thus increasing the degree of social control. The involvement of external actors could, in the best case, induce a trickle-down effect which has a positive effect on all levels of a network. In Romania, this could clearly help to solve the issue of lack of trust which hampers not only forming formal partnerships within LEADER, but also burdens relationship between the agricultural administration and the potential beneficiaries.

At this point it is obvious that the Coordination Committee of the European Network for Rural Development should aim to do more than just its core tasks, collecting and disseminating information. Active coordination between the European Network for Rural Development and the national networks is needed to integrate the Romanian actors and other partners. For partners from new member states this is especially important if they do not have much experience in bottom-up approaches and rural development policies. On the one hand, direct assistance should be offered to support their efforts to establish the National Network for Rural Development, but on the other hand monitoring is also needed. A review process coordinated at European level should also result in possibly critical comments and clear-cut recommendations. However, in the Romanian case, to ensure that these fall on fertile ground, some developments need to take place within the national administration, where at present problems seem not to be open to debate: the MAFRD-website, for example, presents two well developed potential LAGs, but does not address any kind of problematic issues that occurred during the implementation phase of LEADER. The acceptance of external support requires that failures and weaknesses in the implementation of rural development programmes are first acknowledged and accepted.

As seen from the Romanian case, some of the national networks currently exist only on paper. ${ }^{16}$ The Coordination Committee of the European Network for Rural Development could, alongside facilitating the LAGs' search for partners, ${ }^{17}$ also contribute actively in establishing the national networks. For this it is important that the European Network for Rural Development Contact Point has an open ear for all actors and, if possible, is also able to offer direct support.

\section{Conclusions}

The implementation of rural development policies in Romania is severely hampered at present by administrative shortcomings. The responsible programme agencies lack personnel, both in number and in quality. Not only the potential beneficiaries, but also the administrative staff still struggle with the bureaucracy of the programmes. Furthermore, a lack of continuity in programme steering, undue political influence and a lack of trust among the different stakeholders has caused significant delays in the programme implementation. We find that networking can be an effective instrument for alleviating these issues.

In our analysis of the Romanian LEADER programme, which is still in motion, we find that foreign actors especially have contributed to the successful establishment and use of networking activities. The structure and strength of a network influences the chances of a potential LAG to be competitive. Networking has had a clear influence on implementing EU rural development policies in Romania and can be seen as a key factor for their realisation. The implementation of LEADER as the classic networking programme can help prepare the ground for fruitful networking in the national context. LEADER promotes the idea of a participatory approach and partnerships. However, the observed networking activities in some cases tended to be one-sided relations rather than true networking or proper partnerships. External partnerships, through which the Romanian actors obtained technical support, are beneficial and acknowledged to be useful by the actors. If the positive developments are to continue in the longer term, however, these auxiliary relations have to be responded to, which entails the Romanian actors becoming more active. There is good potential for this to happen, if we consider how Romanian LAGs have recently started to network and actively build up external

\footnotetext{
${ }^{16}$ This is also true for Bulgaria for instance.

${ }^{17}$ However, many Romanian actors seem not so far to have discovered the opportunity to avail themselves of the support provided by the Contact Point of the European Network for Rural Development. The Contact Point of the European Network for Rural Development very recently published the list of cooperation announcements and there was no entry registered by a potential Romanian LAG.
} 
partnerships (not only with actors involved in LEADER). Nonetheless, we conclude that more assistance for the (potential) beneficiaries and agencies is needed.

One particularly important effect of networking is an increase in social control. Tight relationships in a network, but also loose connections that are established for example through information sharing, increased publicity and transparency, facilitate the creation of relationships of trust. This is true for LEADER, where external actors often function as mediators by building up trust and partnerships among the various stakeholders involved in integrated rural community development. But it is also one of the reasons why establishing the European Network for Rural Development is important. The network provides a certain degree of social control, which could help overcome issues such as political influence and mutual distrust. Furthermore, the National Network for Rural Development in Romania could become a key element for a rural development policy that is based to the greatest possible extent on continuous debate on local needs and good practice. For the effective implementation of rural development policies in Romania, strengthening relations between the agricultural administration and the (potential) beneficiaries is necessary. This is not only about increasing the capacity of the programme agencies, but also increasing trust. Finally, functioning networks among the Romanian stakeholders involved in rural development policies can lead to smooth management of existing administrative burdens.

In conclusion, the case of Romania shows that formal and informal networking, with their various direct and indirect effects, can be effective instruments for realising rural development policies. But networking depends on a willingness to make the necessary effort and to accept social control - it is an instrument that cannot merely be imposed by EU regulations. The integration of Romanian actors in EU-wide rural networks depends mostly on their own activities, especially those of the responsible persons and organisations at the Romanian national level.

\section{References}

[1] Ciutacu, C. (2008). Social partners in agriculture sector unite to get better deal for producers. Eurofound, EIROnline 06/2008, available at http://www.eurofound.europa.eu/eiro/2008/06/articles/ro0806029i.htm. DOI:R00806029I.

[2] Courades, J.M. (2007, January 31). Rural Development Networking 2007-2013. Presentation at the Joint meeting: LEADER+ Steering Committee, Brussels.

[3] Courades, J.M. (2008a, March 12). Synthesis of Member States Reports. Presentation at the LEADER+ Steering Committee Meeting, Brussels.

[4] Courades, J.M. (2008b, March 12). Member States Reports. Presentation at the LEADER+ Steering Committee Meeting, Brussels.

[5] Dower, M. (2007, October 12-13). Romania Rural Development Network - Proposed structure. Paper presented at the international conference "LEADER - achievements and challenges", Przemyśl.

[6] Duguet, D. (2008, March 12). Cooperation in LEADER+. The actual benefits for local areas. Presentation at the LEADER+ Steering Committee Meeting, Brussels.

[7] Deutsche Vernetzungsstelle Ländliche Räume (Ed.) (2008). 1+1 ist mehr als 2. Handbuch zur gebietsübergreifenden und transnationalen Kooperation. Bonn: German Federal Institute for Agriculture and Food.

[8] European Communities (2006). Der LEADER-Ansatz. Ein grundlegender Leitfaden. Brussels: Office for Official Publications of the European Communities.

[9] Heller, W. (1999). Innenansichten aus dem postsozialistischen Rumänien. Sozioökonomische Transformation, Migration und Entwicklungsperspektiven im ländlichen Raum. Berlin: Berlin Verlag. 
[10] Jacobs, L. (2008, March 12). LEADER networking tools 2007-2013. Presentation at the LEADER+ Steering Committee Meeting, Brussels.

[11] Johnson, B. (1995). Towards a New Approach to National Systems of Innovation. In B.A. Lundvall (Ed.), National Systems of Innovation. Towards a Theory of Innovation and Interactive Learning (23-44). London/New York: Pinter Publishers.

[12] Labar, K., Wegener, S., Petrick, M., Marquardt, D., Theesfeld, I. \& Buchenrieder, G. (2009). Review of Public Service Delivery in Agriculture for Romania and Bulgaria. World Bank. (unpublished report KP-P111199-KMPD-BB).

[13] Law, M., European Network for Rural Development Contact Point (2009 March 30-31). Overview of set up of national and regional networks and first identification of challenges. Presentation on the $1^{\text {st }}$ ENRD Seminar, Brussels.

[14] Loriz-Hoffmann, J. (2008). Das Erbe von LEADER+. LEADER+ Magazine 2008 (9), Brussels: European Commission, Directorate General for Agriculture and Rural Development.

[15] Lückenkötter, J. (2001). Ein Plädoyer für Partnerschaften - Argumente und Anregungen für die ländliche Regionalentwicklung. LEADER forum 2001 (1), 18-29.

[16] Mandl, I., Oberholzner, T. \& Dörflinger, C. (2007). Social capital and job creation in Rural Europe. Dublin: European Foundation for the Improvement of Living and Working Conditions.

[17] Marquardt, D., Dirimanova, V. \& Antal, C. (2009a). Review of Public Service Delivery in Agriculture for Bulgaria and Romania. Results of surveys among farmers about the Public Service Delivery in Agriculture in Romania and Bulgaria. Mimeo, Halle: Leibniz Institute of Agricultural Development in Central and Eastern Europe (IAMO).

[18] Marquardt, D., Möllers, J. \& Buchenrieder, G. (2009b, March 11-14). The relevance of social networks for implementing the LEADER programme in Romania. Paper presented at the $67^{\text {th }}$ International Atlantic Economic Conference, Rome.

[19] Moseley, M.J. (2003). Local Partnerships for Rural Development. The European Experience. London: CABI Publishing.

[20] Nelson, J. \& Farrington J. (1994). Information exchange networking for agricultural development. A review of concepts and practices. Ede: CTA.

[21] Redmann, M. (2008). Assessing the Impact of Rural Development Policies (RuDI). Work Package 2: Rural Development Policy Design, Romania. Tartu: Centre for Ecological Engineering.

[22] Rusu, M. (2008). The Perspectives of the National Rural Development Networks in a European Context. Agricultural Economics and Rural Development 5(1-2), 25-30.

[23] Scott, J. (1991). Social Network Analysis. A Handbook. London: SAGA Publications.

[24] Segert, A. \& Zierke, I. (2004). Ländliche Netzwerke. Institutionalisierungsprozesse und Milieuformationen. Wiesbaden: VS Verlag für Sozialwissenschaften.

[25] Sousa Uva, J.M. (2008, October 16-17). Presentation of the European Network for Rural Development and its Contact Point. Presentation at the Conference 'Europe's rural areas in action: facing the challenges of tomorrow', Cyprus.

[26] Stahl, T. \& Schreiber, R. (2003). Regionale Netzwerke als Innovationsquelle. Das Konzept der >>Lernenden Region<< in Europa. Campus Forschung, Vol. 868, Frankfurt/New York: Campus Verlag.

[27] Stewart, M. (1998). We should build a statue to Ceaucescu here. The trauma of decollectivisation in two Romanian villages. In S. Bridger \& F. Pine (Eds.), Surviving post-socialism. Local strategies and regional responses in Eastern Europe and the former Soviet Union (pp. 66-80), London: Routledge. 
[28] Török, J. (2008, March 12). Facts and figures on cooperation under the LEADER+ initiative. Presentation at the LEADER+ Steering Committee Meeting, Brussels.

[29] World Bank (Ed.) (2008). Implementation completion and Results report (IBRD-46540), on a loan in the amount of US\$40 million to Romania for a Rural development project. World Bank, Environmentally and Socially Sustainable Development Sector Unit, South Central Europe Country Unit, Europe and Central Asia Region. (Report No: ICR0000611).

\section{Legislation}

Commission Decision of 20 February 2008 setting up the organisational structure for the European Network for Rural Development (2008/168/EC).

Commission Notice to the Member States of 14 April 2000 laying down guidelines for the Community initiative for rural development (Leader+) (2000/C 139/05).

Council Regulation of 20 September 2005 on support for rural development by the European Agricultural Fund for Rural Development (EAFRD) (2005/1698/EC).

Council Decision of 20 February 2006 on Community strategic guidelines for rural development (programming period 2007 to 2013) (2006/144/EC).

[NRDP] Romanian Ministry of Agriculture and Rural Development (2008). National Rural Development Programme 2007-2013. Version of 20 February 2008, Bucharest. 